\title{
Physicians Use of Inclusive Sexual Orientation Language During Teenage Annual Visits
}

\author{
Stewart C. Alexander, PhD, J. Dennis Fortenberry, MD, ${ }^{2}$ Kathryn I. Pollak, PhD, ${ }^{3,4}$ \\ Terrill Bravender, MD, MPH, ${ }^{5}$ Truls Østbye, MD, PhD, ${ }^{4}$ and Cleveland G. Shields, $\mathrm{PhD}^{6}$
}

\begin{abstract}
Purpose: Physicians are encouraged to use inclusive language regarding sexuality in order to help all adolescent patients feel accepted. Non-inclusive language by physicians may influence relationships with adolescent patients, especially those with still-developing sexual identities. The aim of this study was to identify patterns of physicians' use of inclusive and non-inclusive language when discussing sexuality.

Method: A total of 393 conversations between 393 adolescents and 49 physicians from 11 clinics located throughout the Raleigh-Durham, North Carolina, area were audio recorded. Conversations were coded for the use of inclusive talk (language use that avoids the use of specific gender, sex, or sexual orientation language), direct non-inclusive talk (language use that assumes the teenager is heterosexual or exclusively engages in heterosexual sexual activity), and indirect non-inclusive talk (language use that frames talk heterosexually but does not pre-identify the adolescent as heterosexual).

Results: Nearly two-thirds $(63 \%, 245)$ of the visits contained some sexuality talk. Inclusive talk rarely occurred (3.3\%) while non-inclusive language was predominant (48.1\% direct and $48.6 \%$ indirect). There were no significant differences in language use by gender, age, adolescent race, or visit length. These non-significant findings suggest that all adolescents regardless of race, gender, or age are receiving non-inclusive sexuality talk from their providers.

Conclusion: Physicians are missing opportunities to create safe environments for teenagers to discuss sexuality. The examples of inclusive talk from this study may provide potentially useful ways to teach providers how to begin sexuality discussions, focusing on sexual attraction or asking about friends' sexual behavior, and maintain these discussions.
\end{abstract}

Key words: adolescents, annual visits, preventive health visits, sexuality.

\section{Introduction}

$\mathbf{M}$ OST SEXUAL MINORITY YOUTH report high levels of adjustment and good relations with family and friends. ${ }^{1,2}$ However, they still have more health risk behaviors, worse health outcomes than other adolescents, and experience much higher rates of harassment, violence, and suicide attempts than non-minority adolescents do. ${ }^{3-14}$ Sexually transmitted infections, including those due to human immunodeficiency virus (HIV) are over-represented among sexual minority youth. ${ }^{15}$ Many of these adverse outcomes are potentially preventable by early identification and intervention with youth who are at risk. Interactions between physicians and sexual minority adolescents provide an opportunity to identify and intervene to support healthy development that may avert adverse health outcomes for at-risk youth.

The American Academy of Pediatrics recommends sexuality discussions with adolescents as an explicit element of health supervision with adolescents. ${ }^{16}$ One challenge faced by physicians is the creation of an environment in which adolescents feel safe in exploring questions of sexual behavior, sexual attraction, and sexual identity. Rigid dichotomous sexual identity labels such as "heterosexual" and "homosexual" may not fit adolescents because sexual behaviors, attractions,

\footnotetext{
${ }^{1}$ Department of Consumer Science, Purdue University, West Lafayette, Indiana.

${ }^{2}$ Department of Pediatrics, Indiana University School of Medicine, Indianapolis, Indiana.

${ }^{3}$ Cancer Prevention, Detection and Control Research Program, Duke University Medical Center, Durham, North Carolina.

${ }^{4}$ Department of Community and Family Medicine, Duke University Medical Center, Durham, North Carolina.

${ }^{5}$ Division of Pediatrics and Communicable Diseases, University of Michigan, Ann Arbor, Michigan.

${ }^{6}$ Department of Human Development and Family Studies, Purdue University, West Lafayette, Indiana.
} 
thoughts, behaviors, fantasies, and identities are still developing and responding to multiple factors in their environments. ${ }^{17-21}$

That sexuality and sexual identity development are fluid and dynamic during adolescence means that patients may benefit when physicians use a clinical approach that is independent of categorical terms such as "heterosexual" and "homosexual" (or any of its associated sexual identity labels). ${ }^{22,23}$ In other words, physicians should be able to discuss issues of sexuality without depending on whether adolescents have adopted a given sexual identity.

In this paper, we use the term "sexual majority" to refer generally to adolescents attracted to different gendered individuals. We use the term "sexual minority" to specify a diverse array of gender and sexual orientations, gender and sexual identities, and gender of preferred partners. Sexual minority includes widely-used words such gay, lesbian, bisexual, transgender, questioning, and queer (GLBTQ) but focuses on social minority status to amplify the stigma and discrimination associated with these labels. ${ }^{24}$ Sexual majority sexuality development and sexual minority sexuality development are not identifiable and distinct entities that can be categorized or predicted reliably. ${ }^{23}$ This perspective on labels is key to our research because the variable, overlapping and fluid trajectories of majority sexuality development and minority sexuality development means that physicians must develop a clinical approach to adolescents that is not exclusive binary terms such as "heterosexual" and "homosexual.",22,25 Use of such terms in clinical interchanges may contribute to sexual minority adolescents perceptions of clinical setting focused on heterosexuality, infrequent discussions of sexuality with providers, and feeling "invisible.,"26

In recent years, a number of scholars have outlined important ways physicians can engage in these discussions to help adolescents, and particularly, sexual minority adolescents feel comfortable and accepted. ${ }^{27-30}$ Language use plays an important role in the physician-patient relationship, and may inadvertently contribute to stigma associated with sexual identity. ${ }^{31-33}$ Even subtle language use may alert teenagers about the safety of disclosures of same-sex attractions or behavior. In fact, the non-inclusive language use in clinical encounters could be a form of "microaggressions" - subtle, unintentional, commonplace verbal usages that convey negative impressions to sexual minority youth. ${ }^{34}$

One approach to addressing issues of sexuality and sexual identity is to use language that is inclusive regarding sexuality and not based on a norm of heterosexuality. Many adolescents have not yet developed the communication skills to identify their own thoughts and feelings about their sexuality, let alone initiate discussions of sexuality with a physician. Many physicians often avoid or truncate even the most basic discussions of sexuality, ${ }^{35}$ so language that assumes heterosexuality may additionally inhibit discussions with sexual minority youth. However, little research directly documents the type of language used by physicians during sexuality discussions with adolescents who are still forming a clear understanding of their sexual attractions and identity.

Based in the idea that inclusive sexual language allows physicians to address sexuality with both sexual majority and sexual minority youth, the aim of this study is to identify the type of sexuality language used by physicians during annual preventive health visits with adolescents. Three categories of lan- guage were assessed: inclusive language that contained gender neutral and inclusive language regarding sexual activity, sexuality, dating, or sexual identity; direct non-inclusive language that explicitly refers to the teenager as heterosexual; and indirect non-inclusive language that assumes heterosexuality but does not directly identify the adolescent as heterosexual.

\section{Methods}

\section{Human subjects approval}

The study was approved by the Duke University School of Medicine Institutional Review Board (IRB) and given exempt status by the Purdue University IRB.

\section{Study overview}

The sexuality conversations analyzed for this study came from the Teen CHAT Study - a randomized, controlled trial teaching physicians how to counsel overweight 12 - to 18 year-olds on obtaining a healthy weight. ${ }^{36}$ Primary care physicians were approached in eleven clinics in the Raleigh-Durham, North Carolina, area (3 academic- and 8 community-based practices). The clinics included rural, suburban, and urban settings.

The Teen CHAT Study was a staggered recruitment design, divided into three consecutive phases: Phase 1 involved the collection of baseline audio recordings between physicians and overweight adolescents; Phase 2 was an Intervention phase in which half of the physicians were taught counseling techniques for their adolescent patients regarding healthy weight: Motivational Interviewing techniques and the use of the $5 \mathrm{~A}$ 's for counseling on achieving healthy weight (Ask, Advise, Assess, Assist, and Arrange); Phase 3 was a Summary Report phase in which physicians were provided with a written summary of the patients' six risk factors linked to obesity (physical activity, screen time, sleep, fast food, breakfast, and consumption of sweetened beverages) based on data collected from the adolescent before the audio recorded visit.

Physicians were recruited in Phase 1 and randomized to either the web-based intervention arm or control arm in Phase 2. Different patients of randomized physicians were recruited in each of the three phases. All preventive health and chronic care visits were audio recorded at all three phases of the Teen CHAT study.

\section{Participants}

For this paper, we included all annual health visits between November 2009 and October 2012, which included adolescent participants from all three phases of the study.

\section{Physicians}

All physicians provided written consent. Physicians consented to have conversations with adolescent patients recorded and analyzed for talk about preventive health topics including sensitive topics such as smoking, drinking, alcohol, and sex. Before each visit, physicians were notified that their conversation was being recorded.

\section{Teenagers and parents}

All 18-year-old adolescent participants provided written consent. For adolescents under 18 years old, adolescents provided written assent, while their parents provided written consent. Adolescents consented to have their visits audio 
recorded with their physician and answered a series of questions related to weight and other sensitive topics.

\section{Measures}

Demographic information was collected from physicians and adolescents after obtaining written consent/assent.

Although the main Teen CHAT study recorded a variety of types of visits such as first time visits, follow-up visits, and health maintenance visits, we only analyzed annual visits for this study because the American Association of Pediatrics (AAP) and American Medical Association (AMA) recommend that during these visits physicians should discuss sexuality development and other preventive health issues such as alcohol, tobacco, and drug use, as well as other safety issues with their adolescent patients. ${ }^{16}$

All visits were audio recorded and later reviewed by two research assistants for all questions (e.g. "Have you started having sex?"), comments (e.g. "I wanted to talk to you today about sex and about birth control."), and discussions related to sexual activity, sexuality, dating, or sexual identity. Sexuality talk varied from one simple comment lasting 3 seconds to a longer, detailed 5-minute discussion. Twenty percent of the audio recordings were double coded for reliability. Disagreements were discussed and final decisions made by consensus. Coders demonstrated strong agreement for sexuality talk (Cohen's Kappa $=0.93$, 97\%; C.I., .96, 1.0). Once all sexuality talk was identified in a conversation, the sexuality talk was transcribed verbatim.

Based on the transcripts, a codebook was developed to code for the type of language used during the conversations. Three styles of sexuality talk were examined: inclusive, direct non-inclusive, and indirect non-inclusive. "Inclusive talk" is defined as physicians' discussion of sex, sexual behaviors, and sexuality while avoiding the use of specific gender, sex, or sexual orientation language (unless it was pertinent to the adolescent's previous statements). When physicians talk with inclusive language, they use gender-neutral language, do not attempt to have the teenager identify or disclose a sexual orientation, and accept the language teenagers use to describe themselves. "Direct non-inclusive talk" is defined as physicians' use of language that assumes the teenager is heterosexual or exclusively engages in heterosexual sexual activity (e.g. "Do you have a girlfriend?"). "Indirect non-inclusive talk" is defined as physicians' discussion of sexuality in a heterosexually framed manner but does not pre-identify the adolescent as heterosexual (e.g. "A lot of teenagers your age are starting to date girls." ). See Table 1 for a summary of definitions and multiple examples of each style.

Two research assistants were trained on the codebook and training consisted of 10 hours over three days. All transcripts were reviewed and coded for types of language use (inclusive, direct non-inclusive, and indirect non-inclusive). Twenty percent of the transcripts were double coded for reliability. Disagreements were discussed and final decisions were made by consensus. Research assistants demonstrated strong reliability (Cohen's Kappa $=.84 ; 95 \%$ CI .72, .97).

\section{Analysis}

We used both quantitative and qualitative analyses. Quantitatively, we examined differences in means and fre- quencies of adolescent demographics, adolescent participation in sexuality talk, and visit characteristics between our three styles of sexuality talk by conducting a series of ANOVAs and $\chi^{2}$ s using SAS 9.3 (Cary, NC). Qualitatively, we used open and focused coding ${ }^{37-43}$ of the sexuality talk transcripts to identify specific communication strategies used by physicians and adolescents. First, we sorted sexuality conversations into three groups based on the language use (inclusive, direct non-inclusive, and indirect non-inclusive). Next, we read transcripts in each group in close detail using an inductive approach to identify themes. As patterns began to emerge, we reviewed the transcripts again to identify specific examples. As a fuller picture of the conversations developed for the specific type of conversation, we compared transcripts side-by-side within the group. After we reviewed and identified the themes in one type of sexuality conversation, we then moved to the other types of sexuality talk and repeated the process again. We did this for all three groups.

\section{Results}

\section{Sample characteristics}

We had a total sample of 393 adolescents (see Table 2). Their mean age was $14.5(\mathrm{SD}=1.9)$. Fifty-three percent were female, $40 \%$ were White, $47 \%$ were Black, and $2 \%$ were other races. We had a total sample of 49 physicians who averaged $41.1(\mathrm{SD}=8.5)$ years of age. Fifty-seven percent were female, $88 \%$ were pediatricians, $88 \%$ were White, 6\% were Black, and 6\% were Asian. Physician completed medical school an average of $12.3(\mathrm{SD}=9.0)$ years ago. The average visit lasted 22.4 minutes. Approximately two-thirds $(63 \% ; 245 / 393)$ of physician-adolescent conversations contained some sexuality talk (data not shown). ${ }^{44}$ Table 2 shows the demographics of the visits that included sexuality talk versus the visits that did not include sexuality talk.

\section{Quantitative analysis}

Table 3 shows that sexually inclusive language was used in $8 / 245(3.3 \%)$ conversations with direct non-inclusive language used in 118/245 (48.1\%) conversations and 119/245 $(48.6 \%)$ used indirect non-inclusive language. There were no significant differences in language use by gender or race. We found no relationship between language use and adolescent age or visit length. In each of the 8 cases in which inclusive language was used, the adolescents were alone with the physician. However, the overall contingency table (Adolescent Alone X Language Use) was not significant (Fisher's exact test, $P=.11$ ). We also examined whether the setting was associated with the use of inclusive language. We found that none of the 16 adolescents seen in rural areas experienced inclusive language. Academic centers accounted for 7 of the encounters and urban centers for 1 of the encounters in which inclusive language was used. However, these differences were not statistically significant (Fisher's exact test, $P=.18)$.

We examined the association between adolescent participation level in sexuality conversations and physician language use and found no significant relationship $\left(\chi^{2}=.55\right)$. The physicians initiated all sexuality discussions. We also 
TABle 1. Definitions With EXAMPLES

\begin{tabular}{|c|c|c|}
\hline Category & Definition & Examples \\
\hline Inclusive & $\begin{array}{l}\text { Sexuality talk where the } \\
\text { physician avoids using } \\
\text { specific gender, sex, or } \\
\text { sexually orientation } \\
\text { language unless it is } \\
\text { pertinent to the } \\
\text { adolescent's previous } \\
\text { statements about sexual } \\
\text { identity, sexual } \\
\text { orientation, or sexual } \\
\text { behavior. }\end{array}$ & $\begin{array}{l}\text { E1: "Any romantic stuff this year? Any crushes?" No. None. "Do you } \\
\text { want to?" No. } \\
\text { E2: "Have you had sex before?" Yes. "How often?" A few times. } \\
\text { "Were these with boys, girls, or both?" } \\
\text { E3: "What about pressures for dating at all?" No. "Have you had sex yet?", } \\
\text { No. "Are you dating anyone?" Yes. "Is this a boyfriend or a girlfriend?" } \\
\text { E4: "Have you ever had sex?" Yes. "Are you sexually active?" No. } \\
\text { "Do you have a partner right now?" Mmm hmm. "And how long } \\
\text { have you been with that partner?" About two months. }\end{array}$ \\
\hline $\begin{array}{l}\text { Direct } \\
\quad \text { Non-Inclusive }\end{array}$ & $\begin{array}{l}\text { Sexuality talk where the } \\
\text { physician assumes the } \\
\text { adolescent is } \\
\text { heterosexual or } \\
\text { exclusively engages in } \\
\text { heterosexual sexual } \\
\text { activity. }\end{array}$ & $\begin{array}{l}\text { E5: "Do you have a boyfriend?" } \\
\text { E6: "What about sex-having sex with girls and stuff like that?", } \\
\text { E7: "And you are a beautiful girl and I am sure boys have approached you. } \\
\text { Any sexual experimenting?" No. "It is all confidential here, we just } \\
\text { want you safe, you can always ask us anything. If you become sexually } \\
\text { active, condoms, condoms, condoms." } \\
\text { E8: “Ok, now about boys. Are you dating a boy now?" } \\
\text { E9: "How many girlfriends do you have? Are you seeing any girls now?" } \\
\text { E10: "Now I am going to ask you something personal. I ask all my teens } \\
\text { this question, so don't be upset. Do you like girls or boys?" Boys. } \\
\text { "Okay, okay. I didn't think you liked girls. But, I have to ask." }\end{array}$ \\
\hline $\begin{array}{l}\text { Indirect } \\
\quad \text { Non-Inclusive }\end{array}$ & $\begin{array}{l}\text { Sexuality talk that assumes } \\
\text { heterosexual sex but } \\
\text { does not presume the } \\
\text { adolescent Is } \\
\text { heterosexual. }\end{array}$ & $\begin{array}{l}\text { E11: "Boyfriend and girlfriend. People who have sex together. Do you } \\
\text { have any questions about that? Have you started doing that stuff?" } \\
\text { E12: "And I always tell my teens is if someone is going to have sex } \\
\text { before marriage they should always always, always use a condom } \\
\text { and birth control. Every single time." } \\
\text { E13: "Anytime people have sex there are two major things we worry } \\
\text { about: pregnancy and infections. There are a lot of infections } \\
\text { out there. The best way people can avoid these things is to use } \\
\text { condoms and birth control." }\end{array}$ \\
\hline
\end{tabular}

examined whether the Teen CHAT intervention was associated with differences in inclusive language use, but found that the cell sizes for inclusive language were too small for a logistic regression analysis to be valid.

\section{Qualitative analysis}

Using qualitative methods, we used open and focused coding $^{37-43}$ of the sexuality talk based on type of language use. Inclusive language talk was often initiated in one of two ways: by focusing on attraction and by asking about friends. Physicians who used inclusive language used three techniques to maintain this style of sexuality talk: normalizing and legitimizing different attractions; emphasizing non-judgment; and allowing for additional discussion. Sexuality discussions of physicians using non-inclusive language discussions were characterized by numerous pauses and hesitations, and by very rapid changes in topic.

\section{Starting the inclusive conversation}

Focusing on attraction. Physicians who used inclusive talk often focused on attraction rather than behavior. Five of the eight inclusive conversations began this way with two additional conversations incorporating attraction into their discussions early in the discussion. The use of attraction language suggests an effort to understand a teenager's sexual identity rather than staying focused on sexual behavior. This type of language was exemplified by phrases such as, "I know some teenagers who are attracted to girls, I know some teenagers who are attracted to boys, and I know some teenagers who are attracted to both. Have you started to think about these things?" "Usually girls your age start to become interested in boys or other girls or both, have you started to become interested in others?"; and, "A lot of kids I talk to who are your age are starting to figure out who they are attracted to, and some guys tell me they are attracted 
Table 2. Subject Characteristics of Those With SeXuality TalK

\begin{tabular}{lcc}
\hline Variables & Mean/\% & $S D$ \\
\hline Adolescents $(n=245)$ & & \\
Age & 14.6 & 1.6 \\
Female & $56 \%$ & \\
Race & $38 \%$ & \\
$\quad$ White & $49 \%$ & \\
Black & $12 \%$ & \\
Other & & \\
Setting & $44.1 \%$ & \\
Academic & $6.5 \%$ & \\
Rural & $49.4 \%$ & \\
Urban & & \\
Physician $(n=49)$ & 40.5 \\
Age & $61 \%$ & \\
Female & $90 \%$ & \\
Pediatrician & & \\
Race & $90 \%$ & \\
$\quad$ White & $7 \%$ & \\
Black & $3 \%$ & \\
Asian & 12.27 & \\
Years Since Medical School & & \\
\hline
\end{tabular}

to girls, some say guys, and some say both. Some say they haven't figured it out yet. Have you?" In all cases, physicians usually tried to provide a larger context to the question regarding attraction to help shape the idea that there are more than one type of attraction possible for teenagers.
Asking about friends. The other way physicians began inclusive sexuality talk was by asking about the teenager's friends and their sexual activity. Three out of eight inclusive sexuality conversations began with questions about the teen's friends and two additional conversations picked up this line of questioning as well. Approaches such as, "Have any of your friends started dating? Any boyfriends or girlfriends or both?" "Do you know if your friends started to have sex yet?" and, "Are your friends dating?" Physicians used this approach to then turn to the teenager's dating and sexual behavior by always using gender-neutral or absent terms, such as "anybody,", "someone," or " partners" when asking about the teenager's sexual activity.

\section{Maintaining an inclusive conversation}

Normalizing and legitimizing different attractions. One of the common means used by physicians to maintain inclusive talk was reinforcing the notion of multiple attractions and identities. We heard this in all but two of the inclusive discussions. Physicians often followed-up on questions about attraction with statements such as, "That's important to ask because a lot of teenagers may have different things they are attracted to right?" "People like all different kinds of people: male, female, both; black, white, green, red. Don't let anyone tell you who you should like." and, "I see teens of all types and I tell them the same thing: Be yourself."

Emphasizing non-judgment. One way that physicians maintained inclusive talk was to stress non-judgment when talking with teenagers. We heard this in five of the inclusive

Table 3. Sexuality Discussion Style by Adolescent, Physician, and Visit Characteristics

\begin{tabular}{|c|c|c|c|}
\hline & Inclusive & Direct Non-Inclusive & Indirect Non-Inclusive \\
\hline $\begin{array}{l}\text { Total, } n(\%) \\
\text { Adolescent }\end{array}$ & $8(3.3 \%)$ & $118(48.2 \%)$ & $119(48.6 \%)$ \\
\hline $\begin{array}{l}\text { Gender } \\
\quad \text { Male, } n(\%) \\
\text { Female, } n(\%)\end{array}$ & $\begin{array}{l}3(0.6 \%) \\
5(1.2 \%)\end{array}$ & $\begin{array}{l}53(21.6 \%) \\
65(26.5 \%)\end{array}$ & $\begin{array}{l}52(21.2 \%) \\
67(27.4 \%)\end{array}$ \\
\hline $\begin{array}{l}\text { Participation } \\
\quad(>\text { Yes or No response })\end{array}$ & $4(1.6 \%)$ & $72(29.4 \%)$ & $65(26.5 \%)$ \\
\hline $\begin{array}{l}\text { Race } \\
\text { White, } n(\%) \\
\text { Black, } n(\%) \\
\text { Asian, } n(\%) \\
\text { Native, } n(\%) \\
\text { Multi-racial }\end{array}$ & $\begin{array}{l}3(1.2 \%) \\
4(1.6 \%) \\
0(0 \%) \\
0(0 \%) \\
0(0 \%)\end{array}$ & $\begin{aligned} 35 & (14.3 \%) \\
64 & (26.1 \%) \\
2 & (0.8 \%) \\
1 & (0.4 \%) \\
13 & (5.3 \%)\end{aligned}$ & $\begin{aligned} 49 & (20.0 \%) \\
57 & (23.3 \%) \\
1 & (0.4 \%) \\
0 & (0 \%) \\
8 & (3.3 \%)\end{aligned}$ \\
\hline $\begin{array}{l}\text { Missing }=8 \\
\text { Age } \\
\quad \text { Years (SD) }\end{array}$ & $14.3(1.6)$ & $14.7(1.7)$ & $14.5(1.6)$ \\
\hline $\begin{array}{l}\text { Visit } \\
\quad \min (\mathrm{SD})\end{array}$ & $28.0(11.4)$ & $24.6(9.3)$ & $23.5(9.0)$ \\
\hline $\begin{array}{l}\text { Setting } \\
\text { Academic } \\
\text { Rural } \\
\text { Urban }\end{array}$ & $\begin{array}{l}7 \\
0 \\
1\end{array}$ & $\begin{array}{r}52 \\
8 \\
58\end{array}$ & $\begin{array}{r}49 \\
8 \\
62\end{array}$ \\
\hline $\begin{array}{l}\text { Adolescent Alone } \\
\text { No } \\
\text { Yes }\end{array}$ & $\begin{array}{l}0(0.0 \%) \\
8(3.3 \%)\end{array}$ & $\begin{array}{l}29(11.8 \%) \\
89(36.3 \%)\end{array}$ & $\begin{array}{c}19(7.7 \%) \\
100(40.8 \%)\end{array}$ \\
\hline
\end{tabular}


discussions. For instance, one physician reassured a boy who was reluctant to talk about sex by saying:

\begin{abstract}
"Whenever you are ready I am here for you, ok? This is a safe place. I want you to know that. It is not about judgments. You should never feel judged. Ever. If you ever do, I want to know about it. You should be able to come here and be yourself. Whatever that is. Whoever that is. Just so you know, I am here for you. I am your doctor."
\end{abstract}

Other physicians explicitly stated,

"I want you to know that I am here for you and regardless of who you are interested in or become interested in, I want to be sure I can provide you the proper care."

In almost all the instances of non-judgment, the physician did not try to force the teenager to disclose their attractions or preferences, rather they asked and then followed-up with their reassuring statements regarding their care for the teenager.

Leaving the door open. In three of the inclusive discussions, physicians explicitly mention to the teenager that "it is okay if you don't really know right now or haven't thought about it," and, "If things change or, if along the way you decide something else is right for you, I want you to let me know.'

Non-inclusive conversations. Because our qualitative analysis revealed similar categories for both direct and indirect non-inclusive talk, we merged the two types of conversations into the broader category of non-inclusive talk. During our analysis, we found two interaction sequences that physicians often used when talking non-inclusively: discomfort when discussing a sexuality conversation; and starting with a sexuality discussion then quickly changing the subject.

Discomfort. After starting a sexuality conversation, some physicians showed verbal discomfort with the topic: approximately $20 \%$ of the indirect and $15 \%$ of the direct non-inclusive discussions. For these conversations, physicians often repeating partial statements and using vocal fillers such as "ummm," "errs," and "uhs":

"Uh. So this is....(pause) Uh, this is the point (pause) where we (longer pause) where we.... (longer pause) Uh.... (pause) Now, I don't want to get you upset. It is just that.... (pause) It's just that we just sometimes ask.... (pause) Cause we need, uh, we need to know.'

Because our data were based on audio recordings, physicians may have been responding to non-verbal cues to their patient's discomfort with sexuality talk, this we will never know. However, careful review of the audio recordings rarely suggested adolescents' expressing discomfort with questions of sexual attraction or identity.

Quickly changing the topic. Quickly changing the topic after an initial question or statement about sexual activity was common: $40 \%$ of indirect and $38 \%$ of direct non-inclusive discussions. Seventy percent (35 out of 49) physicians had at least one example of this approach. Examples of doctor/ patient conversations include:
"Tried any cigarettes? Alcohol? Illegal drugs? Sexual activity of any kind?"

"Uh, no."

"Good. What about school? Going well? Any problems there? And do you have a girlfriend?"

"No."

"Ok, what about your moods? Have you been depressed lately?"

And:

"I always tell my teens, if you were to be sexually active, he has to wear a condom, every single time because of diseases and pregnancy. We don't want that. Ok. Tell me about your energy these day."

By changing the topic so quickly, physicians were able to cover the topic of sexuality, which is one of the AAP's recommended preventive health topics that be should be covered during an annual visit, without exploring or providing guidance regarding the topic.

\section{Discussion}

We examined inclusive language in provider-adolescent sexuality talks during annual visits and found that, in our sample, physicians rarely discussed sexuality in inclusive ways and only in $3 \%$ of all visits. We found no physician, visit, or teenager characteristics that were associated with inclusive language use. We also found no relationship between teen participation level in sexuality conversations and inclusive language use.

Physicians took a variety of approaches to inclusive language. Sometimes they asked teens to whom they were attracted or would ask them about their friends attractions, sexual behavior, and with which gender they were doing what. Occasionally, they would focus on sexual identity rather than behavior. Those physicians who maintained inclusive language frequently used language that implied acceptance by talking about how normal it may be for some to be attracted to people of different genders. In some cases, physicians would explicitly state that they were a safe person with whom adolescents could talk about sexual behavior and encourage them to return if and when they had any questions. Essentially, in these encounters physicians were able to create an atmosphere of safety for adolescents where non-majority sexuality could be discussed. These various approaches are recommended within the literature regarding sexual development. ${ }^{45-47}$

In non-inclusive conversations, even when physicians began with inclusive language, they would negate it, likely foreclosing additional exploration about the adolescents' sexual behavior and attractions. Non-inclusive conversations were characterized by behaviors that we interpreted as signs of discomfort with the general topic of sexuality and about sexual identity such as verbal hesitancy and lack of word precision. Our results echo those that have also found that physicians often cite their own discomfort among reasons for omission of sexual history and discussions of sexual behavior. ${ }^{48,49}$

Our study appears to be one of the first to examine the use of inclusive language during a medical encounter with adolescent patients because we could find no other studies of inclusive language use during such encounters. However, inclusive language use has been endorsed in the literature. The Gay and Lesbian Medical Association, in a companion document to the Institute of Medicine's (IOM) report, Healthy People 2010, recommends the use of inclusive language in conversations 
and documents in medical offices. ${ }^{50}$ LGBT youth ranked good interpersonal skills of providers as their first concern followed by experience with LBGT populations and inclusive language use. ${ }^{51,52}$ Educators recommend inclusive language in the classroom. ${ }^{53}$ While groups have recommended the use of inclusive language, we have shown that it rarely happened in our sample. We also found no studies that examined associations of inclusive language use with LGBT adolescent outcomes such as satisfaction, greater disclosure about sexual behavior, increased knowledge about sexuality, increased safer sex practices, reduced sexual risk taking, or improved mental health. These studies remain to be done.

\section{Implications for training}

Given our conceptualization of adolescent sexual development as a fluid process that may not include dichotomous descriptions of young adolescents' orientation, inclusive language use may increase the effectiveness of health supervision for improving adolescents' sexual health and reducing risk of adverse consequences of sex. This type of interviewing skill can be accomplished by addressing physicians' own values related to sexuality, by increasing their understanding of the health relevance of adolescent sexuality, and by skills building practice.

\section{Limitations}

There are several limitations to this study: First, no sexual orientation demographic information was collected from either the adolescent or the physician. Yet, we believe that sexuality talk in an inclusive manner does not require knowing an adolescent's sexual orientation. If we had had self-report data about adolescents' or providers' sexual behavior, we could have examined whether providers were less comfortable with sexual minority youth or whether sexual minority physicians talked differently with adolescents; Second, the visits were all from the southeast area of the United States and may not generalize to other areas in the United States. However, we purposefully collected data from both academically-affiliated and community-affiliated clinics as well as clinics in rural, suburban, and urban settings to provide a wide range of visits. However, because this part of the country is known to be more conservative about sexuality, the use of inclusive language may be lower than may be found in other parts of the country; Third, all adolescents in this study had BMI z-score $\geq 85$ th for age/gender. Although all the adolescents were overweight, there is no theoretical reason why sexuality talk should differ compared to other adolescents. In fact, some studies have found that overweight adolescents are more likely to engage in risky sexual behaviors $^{55,56}$ and that LGBT youth may be more likely to be overweight. ${ }^{5}$ Fourth, adolescents and physicians were aware that they were being audio recorded. Thus, having an audio recorder in the room may have altered any sexuality talk; Finally, we did not analyze other health care providers, such as, physician assistants, nurse practitioners, nurses, and other health care workers. Future studies examining these other groups would aid in better understanding the larger healthcare environment that adolescents navigate.

\section{Future research}

We propose that the next step is to conduct intervention studies that compare communication strategies for initiating and carrying-on sexuality discussions with adolescents. Interventions could compare conversations that start with sexual behavior, as we described above, versus those that start with asking broad questions about sexual knowledge. Because LGBT adolescents are at-risk for adverse health outcomes such as obesity, smoking, drug and alcohol abuse, and homelessness, ${ }^{10,11,13,57}$ it is important that primary care providers develop strong relationships with them to provide preventive services. While there is growing acceptance of diverse LGBT communities in the US, many adolescents remain confused and unsupported and at risk for bullying and rejection by peers, some religious communities, and family members. ${ }^{8,58,59}$ Additionally, studies could examine and help bring awareness to physicians use of subtle, unintentional, and commonplace non-inclusive language and teach physicians ways to avoid this language during sexuality talk with teenage patients. It is vital we investigate the most successful communication strategies for engaging adolescents as their sexuality and sexual identity develop.

We also propose that intervention studies should also examine ways to increase physicians' self-efficacy, awareness, and comfort in discussing sexuality because research shows that experience alone does not improve communication. ${ }^{54}$ These training programs should focus on teaching how to reinforce effective communication principles with adolescents such as establishing an open environment for sex discussions, demonstrating empathy, promoting autonomy; learning effective techniques with adolescents like the use of sexuality unbiased statements, focusing on behavior counseling, using non-judgmental statements; increasing self-efficacy and confidence in communicating effectively with adolescents about sex and sexuality such as having physicians practice and receive positive reinforcement; and addressing specific sexual minority healthy issues like assessing psychological distress, previous victimization and high risk behaviors. ${ }^{30,57,60-64}$ Studies should examine ways to make such training easy for physicians to access and immediately applicable to their practice needs.

\section{Conclusion}

Physicians almost never used inclusive language when discussing sexuality with adolescents but typically used non-inclusive language. Non-inclusive language was almost evenly split between direct and indirect non-inclusive language. There were no significant differences in language use by gender, age, adolescent race, or visit length. The results show that physicians are missing important opportunities to create safe environments for teenagers to discuss sexuality. Inclusive language allows safe and confidential discussion of diverse attractions, identity, and behaviors. Because many adolescents' sexual identities are still forming, physicians need to create an environment for adolescents to talk about sexuality without a priori assumptions about sexual orientation, sexual identity or sexual behavior.

\section{Practical implications for healthcare providers}

Although rarely done, physicians may play important roles in creating safe environments for adolescents to talk about sexuality. These discussions may provide comfort and guidance in navigating the sometimes-confusing journey of adolescent sexual development. Maintaining the use of inclusive language during the interview may offer adolescents opportunities to 
think about and discuss their own developing sexuality at that visit and at future visits. Although talking in an inclusive manner may be difficult, at first, for physicians, it is a skill that can be learned and we recommend be integrated into routine clinical care for adolescents. We suggest starting with inquiries about sexual behavior and following the adolescents' lead whether to discuss attractions or identity. If the adolescent discusses being attracted to one person or gender, follow along but don't steer the conversation. If adolescents speak about sexual identity, allow them to continue. If they talk about difficulties, validate their concerns as a normal part of developing a sexual identity. When adolescents are struggling, it is also important to assess for depression, anxiety, or suicidal ideation.

\section{Acknowledgments}

We wish to thank James Tulsky for feedback on writing an early version of our manuscript. We wish to thank Kelly Davis with assistance in coding and thank Alicia Bilheimer for her work as our Project Coordinator and for helping in all stages of our project. We wish to thank Sidney Graves and Alexis Irons, who provided assistance with data collection. We thank all adolescents, parents, and physicians who allowed us to record their preventive health visits. This study was funded by the National Heart, Lung, and Blood Institute (R01HL092403). Dr. Alexander had full access to all the data in the study and takes responsibility for the integrity of the data and the accuracy of the data analysis.

\section{Author Disclosure Statement}

No competing financial interests exist.

\section{References}

1. Ryan C, Russell ST, Huebner D, Diaz R, Sanchez J: Family acceptance in adolescence and the health of LGBT young adults. J Child Adolesc Psychiatr Nurs 2010;23:205-213.

2. Goodenow C, Szalacha L, Westheimer K: School support groups, other school factors, and the safety of sexual minority adolescents. PITS 2006;43:573-589.

3. Coker TR, Austin SB, Schuster MA: The health and health care of lesbian, gay, and bisexual adolescents. Annu Rev Public Health 2010;31:457-477.

4. Jun H-J, Austin SB, Wylie SA, et al.: The mediating effect of childhood abuse in sexual orientation disparities in tobacco and alcohol use during adolescence: results from the Nurses' Health Study II. Cancer Causes Control 2010;21:1817-1828.

5. Austin SB, Ziyadeh NJ, Corliss HL, et al.: Sexual orientation disparities in weight status in adolescence: findings from a prospective study. Obesity (Silver Spring) 2009;17:1776-1782.

6. Austin SB, Ziyadeh NJ, Corliss HL, et al.: Sexual orientation disparities in purging and binge eating from early to late adolescence. J Adolescent Health 2009;45:238-245.

7. Roberts AL, Austin SB, Corliss HL, et al.: Pervasive trauma exposure among US sexual orientation minority adults and risk of posttraumatic stress disorder. Am J Public Health 2010;100:2433-2441.

8. Berlan ED, Corliss HL, Field AE, et al.: Sexual orientation and bullying among adolescents in the growing up today study. J Adolescent Health 2010;46:366-371.

9. Garofalo R, Wolf RC, Wissow LS, et al.: Sexual orientation and risk of suicide attempts among a representative sample of youth. Arch Pediatr Adolesc Med 1999;153:487-493.
10. Talley AE, Hughes TL, Aranda F, et al.: Exploring alcoholuse behaviors among heterosexual and sexual minority adolescents: intersections with sex, age, and race/ethnicity. Am J Public Health 2014;104:295-303.

11. Stone DM, Luo F, Ouyang L, et al.: Sexual orientation and suicide ideation, plans, attempts, and medically serious attempts: evidence from local Youth Risk Behavior Surveys, 2001-2009. Am J Public Health Feb 2014;104: 262-271.

12. Russell ST, Everett BG, Rosario M, et al: Indicators of victimization and sexual orientation among adolescents: analyses from Youth Risk Behavior Surveys. Am J Public Health 2014;104:255-261.

13. Rosario M, Corliss H, Everett B, et al.: Sexual orientation disparities in cancer-related risk behaviors of tobacco, alcohol, sexual behavior, and diet and physical activity: pooled Youth Risk Behavior Surveys. Am J Public Health 2014; 104:245-254.

14. Newcomb ME, Birkett M, Corliss HL, et al.: Sexual orientation, gender, and racial differences in illicit drug use in a sample of US high school students. Am J Public Health 2014;104:304-310.

15. Centers for Disease Control and Prevention: Results of the Expanded HIV Testing Initiative-25 jurisdictions, United States, 2007-2010. MMWR Morb Mortal Wkly Rep 2011;60): 805-810.

16. Hagan J, Shaw J, Duncan P, eds.: Bright Futures: Guidelines for Health Supervision of Infants, Children, and Adolescents. 3rd ed. Elk Grove Village, IL: American Academy of Pediatrics, 2008.

17. Worthington RL, Savoy HB, Dillon FR, et al.: Heterosexual identity development: a multidimensional model of individual and social identity. The Counseling Psychologist 2002;30: 496-531.

18. Worthington RL, Mohr JJ: Theorizing heterosexual identity development. The Counseling Psychologist 2002;30:491-495.

19. Eliason MJ: Accounts of sexual identity formation in heterosexual students. Sex Roles 1995;32:821-834.

20. Morgan EM, Steiner MG, Thompson EM: Processes of sexual orientation questioning among heterosexual men. Men \& Masculinities 2010;12:425-443.

21. Boratav HB: Making sense of heterosexuality: an exploratory study of young heterosexual identities in turkey. Sex Roles 2006;54:213-225.

22. Striepe MI, Tolman DL: Mom, dad, I'm straight: the coming out of gender ideologies in adolescent sexual-identity development. J Clin Child Adolesc Psychol 2003;32:523-530.

23. Diamond LM: New paradigms for research on heterosexual and sexual-minority development. J Clin Child Adolesc Psychol 2003;32:490-498.

24. Lichtenstein B: Stigma as a barrier to treatment of sexually transmitted infections in the American deep south: issues of race, gender, and poverty. Soc Sci Med 2003;57:24352445.

25. Archer SL, Grey JA: The sexual domain of identity: sexual statuses of identity in relation to psychosocial sexual health. Identity: An International Journal of Theory and Research 2009;9:33-62.

26. Frankowski B: Sexual orientation and adolescents. Pediatrics 2004; 113:1827-1832.

27. Tulloch T, Kaufman M: Adolescent sexuality. Pediatr Rev 2013;34:29-37; quiz 38.

28. Farrisi D: Counseling adolescents about sexual health risk and safer sex. HIV Clin 2012;24:11-12. 
29. Ham P, Allen C: Adolescent health screening and counseling. Am Fam Physician 2012;86:1109-1116.

30. Macdowall W, Parker R, Nanchahal K, et al.: 'Talking of Sex': developing and piloting a sexual health communication tool for use in primary care. Patient Educ Couns 2010; 81:332-337.

31. Althof SE, Rosen RC, Perelman MA, et al.: Standard operating procedures for taking a sexual history. J Sex Med 2013;10:2635.

32. Committee on Adolescence: Office-based care for lesbian, gay, bisexual, transgender, and questioning youth. Pediatrics 2013;132:198-203.

33. Chaplic KC, Allen PJ: Best practices to identify gay, lesbian, bisexual, or questioning youth in primary care. Pediatr Nurs 2013;39:99-103.

34. Nadal K: That's so gay!: Microaggresions and the lesbian, gay, bisexual, and transgender community. Washington, DC: American Psychological Association, 2013.

35. Kitts R: Barriers to optimal care between physicians and lesbian, gay, bisexual, transgender, and questioning adolescent patients. J Homosex 2010;57:730-747.

36. Bravender T, Tulsky JA, Farrell D, et al.: Teen CHAT: Development and utilization of a web-based intervention to improve physician communication with adolescents about healthy weight. Patient Educ Couns 2013;93:525-531.

37. Ahles TA, Wasson JH, Seville JL, et al.: A controlled trial of methods for managing pain in primary care patients with or without co-occurring psychosocial problems. Ann Fam Med 2006; 4:341-350.

38. Borkan J: Immersion/crystallization. In: Doing qualitative research. Edited by Crabtree BF, Miller WL.Thousand Oaks, CA: Sage; 1999, pp 179-194.

39. Charmaz K: Constructing grounded theory: a practical guide through qualitative analysis. Thousand Oaks, CA: Sage, 2006.

40. Crabtree BF, Miller WL: Using codes and code manuals: a template organizing style of interpretation. In: Doing Qualitative Research. Edited by Crabtree BF, Miller WL. Thousand Oaks, CA: Sage; 1999, pp 163-177.

41. Lindlof TR, Taylor BC: Qualitative communication research methods, 2nd ed. Thousand Oaks, CA: Sage, 2002.

42. Lofland J, Snow D, Anderson L, et al.: Analyzing Social Settings: A Guide to Qualitative Observation and Analysis. Belmont, CA: Wadsworth/Thomson Learning, 2006.

43. Strauss A, Corbin J: Basics of Qualitative Research: Techniques and Procedures for Developing Grounded Theory. Thousand Oaks, CA: Sage, 1998.

44. Alexander SC, Fortenberry JD, Pollak KI, et al.: Sexuality talk during adolescent health maintenance visits. JAMA Pediatr 2014;168:163-169.

45. Mustanksi B, Kuper L, Greene G: Development of sexual orientation and identity. In: Handbook of Sexuality and Psychology. Edited by Tolman D, Diamond LM. Washington, DC: American Psychological Association, 2013:597-628.

46. Rosario M, Schrimshaw E: Theories and etiologies of sexual orientation. In: Handbook of Sexuality and Psychology. Edited by Tolman DL, Diamond LM. Washington DC: American Psychological Association, 2013:555-596.

47. Mustanski B, Birkett M, Greene GJ, et al.: The association between sexual orientation identity and behavior across race/ethnicity, sex, and age in a probability sample of high school students. Am J Public Health 2014;104:237-244.

48. Skelton JR, Matthews PM: Teaching sexual history taking to health care professionals in primary care. Med Educ 2001;35:603-608.
49. Shindel AW, Ando KA, Nelson CJ, et al.: Medical student sexuality: how sexual experience and sexuality training impact U.S. and Canadian medical students' comfort in dealing with patients' sexuality in clinical practice. Acad Med 2010;85:1321-1330.

50. Gay and Lesbian Medical Association (GLMA) and LGBT health experts: Healthy people 2010 companion document for lesbian, gay, bisexual, and transgender (LGBT) health. San Francisco, CA: Gay and Lesbian Medical Association, 2001.

51. Ginsburg K, Winn R, Rudy B, et al.: How to reach sexual minority youth in the health care setting: the teens offer guidance. J Adolesc Health 2002;31:407-416.

52. Hoffman N, Freeman K, Swann S: Healthcare preferences of lesbian, gay, bisexual, transgender and questioning youth. J Adolesc Health 2009;45:222-229.

53. Schniedewind N, Cathers K: Becoming allies for each other: an inclusive approach for confronting heterosexism in schools. Equit Excell Educ. 2003;36:184-193.

54. Kurtz S, Silverman J, Draper J: Teaching and Learning Communication Skills in Medicine. Oxon, UK: Radcliffe Publishing Ltd., 2005.

55. Leech T, Dias J: Risky sexual behavior: a race-specific social consequence of obesity. J Youth Adolesc 2012;41: 41-52.

56. Averett S, Corman H, Reichman N: Effects of overweight on risky sexual behavior of adolescent girls. Econ Inq 2013;51:605-619.

57. Newcomb ME, Heinz AJ, Birkett M, et al.: A longitudinal examination of risk and protective factors for cigarette smoking among lesbian, gay, bisexual, and transgender youth. J Adolesc Health 2014;54:558-564.

58. Ryan C, Huebner D, Diaz RM, et al.: Family rejection as a predictor of negative health outcomes in white and Latino lesbian, gay, and bisexual young adults. Pediatrics 2009;123: 346-352.

59. Harrison TW: Adolescent homosexuality and concerns regarding disclosure. J Sch Health 2003;73:107-112.

60. D’Amico EJ, Osilla KC, Hunter SB: Developing a group motivational interviewing intervention for adolescents atrisk for developing an alcohol or drug use disorder. Alcohol Treat Q 2010;28:417-436.

61. Laidlaw TS, Kaufman DM, Sargeant J, et al.: What makes a physician an exemplary communicator with patients? Patient Educ Couns 2007;68:153-160.

62. Pollak KI, Alexander SC, Tulsky JA, et al.: Physician empathy and listening: associations with patient satisfaction and autonomy. J Am Board Fam Med 2011;24:665-672.

63. Pollak KI, Alexander SC, Ostbye T, et al.: Primary care physicians' discussions of weight-related topics with overweight and obese adolescents: results from the Teen CHAT pilot study. J Adolesc Health 2009;45:205-207.

64. Committee on Adolescence: Office-based care for lesbian, gay, bisexual, transgender, and questioning youth. Pediatrics 2013;132:198-203.

Address correspondence to: Stewart Alexander, PhD Department of Consumer Sciences 700 W. State Street West Lafayette, IN 47907

E-mail: alexan90@purdue.edu 


\section{This article has been cited by:}

1. Alexis L. Rossi, Eliot J. Lopez. 2017. Contextualizing Competence: Language and LGBT-Based Competency in Health Care. Journal of Homosexuality 64:10, 1330-1349. [CrossRef]

2. Lindsay Fuzzell, Cleveland G. Shields, Stewart C. Alexander, J. Dennis Fortenberry. 2017. Physicians Talking About Sex, Sexuality, and Protection With Adolescents. Journal of Adolescent Health 61:1, 6-23. [CrossRef]

3. Alec W Gibson, Asa E Radix, Shail Maingi, Shilpen Patel. 2017. Cancer care in lesbian, gay, bisexual, transgender and queer populations. Future Oncology 13:15, 1333-1344. [CrossRef]

4. Maria K. Venetis, Beth E. Meyerson, L. Brooke Friley, Anthony Gillespie, Anita Ohmit, Cleveland G. Shields. 2017. Characterizing Sexual Orientation Disclosure to Health Care Providers: Lesbian, Gay, and Bisexual Perspectives. Health Communication 32:5, 578-586. [CrossRef]

5. Betsy Pfeffer, Taylor Rose Ellsworth, Melanie A. Gold. 2017. Interviewing Adolescents About Sexual Matters. Pediatric Clinics of North America 64:2, 291-304. [CrossRef]

6. Lindsay Fuzzell, Heather N. Fedesco, Stewart C. Alexander, J. Dennis Fortenberry, Cleveland G. Shields. 2016. "I just think that doctors need to ask more questions": Sexual minority and majority adolescents' experiences talking about sexuality with healthcare providers. Patient Education and Counseling 99:9, 1467-1472. [CrossRef]

7. Gwendolyn P. Quinn, Julian A. Sanchez, Steven K. Sutton, Susan T. Vadaparampil, Giang T. Nguyen, B. Lee Green, Peter A. Kanetsky, Matthew B. Schabath. 2015. Cancer and lesbian, gay, bisexual, transgender/transsexual, and queer/questioning (LGBTQ) populations. CA: A Cancer Journal for Clinicians 65:5, 384-400. [CrossRef] 